\title{
Directional Drilling and Stimulation of a Deep Sedimentary Geothermal Reservoir
}

\author{
by Ernst Huenges, Inga Moeck, and the Geothermal Project Group
}

doi:10.2204/iodp.sd.5.08.2007

\section{Introduction}

Strata of Lower Permian sandstones and volcanics are widespread throughout Central Europe, forming deeply buried (on average, 4000-m) aquifers in the North German Basin with formation temperatures of up to $150^{\circ} \mathrm{C}$. Stimulation methods to increase their permeability by enhancing or creating secondary porosity and flow paths are investigated by deep drilling. The goal is to map the potential for the generation of geothermal electricity from such deep sedimentary reservoirs using a doublet of boreholes-one to produce deep natural hot water and the other to re-inject the water after use. For these purposes, an in situ downhole laboratory was established in Gross Schönebeck, north of Berlin, Germany (Fig. 1).

At present, two 4.3-km-deep boreholes have been drilled. The first well (GrSk 3/90), originally completed in 1990 as a gas exploration well abandoned due to non-productivity, was reopened in 2000 and hydraulically stimulated in several treatments between 2002 and 2005. In 2006, the second well (GrSk 4/05), planned for extraction of thermal waters, was drilled to form a doublet system of hydraulically connected boreholes. In this second well the Lower Permian sandstones and the underlying volcanic rock are targeted for stimulation by hydrofracturing. The resulting reservoir should have an increased productivity with a minimal requirement for auxiliary energy to drive the thermal water loop (reservoir-surface-reservoir) and with minimal risk of a temperature short circuit of the system during the planned 30-year utilization period. The current experiment is designed to demonstrate sustainable hot water production from the reservoir between the two wells.

\section{Background}

Increasing demands for renewable energy are leading to utilization of geothermal resources from areas with typical (low) continental thermal gradients, as found in western and central Europe. For the exploitation of such low-enthalpy reservoirs, it is necessary to enhance the geothermal system. Two basic technologies based on hydraulic fracturing of the reservoir by variations in fluid pressure (Economides and Nolte, 1989; Huenges and Kohl, 2007) can be applied:

- creation of an artificial heat exchanger at depth and using surface water for heat extraction from mostly dry rocks, e.g., Soultz-sous-Forêts (Baumgärtner et al., 2004)

- creation of artificial pathways at depth to enhance the water flow from water-bearing reservoir rocks, e.g., Gross Schönebeck (Huenges et al., 2004).

Lower Permian strata comprising upward fining siliciclastic rocks underlain by volcanic rocks (Fig. 1) are well-known from extensive gas exploration and production in NE Germany. Suitable framing for the study includes (1) formation temperatures above $120^{\circ} \mathrm{C}$, in rocks at $>3000 \mathrm{~m}$ depths, (2) large and regional extent of representative reservoir rocks, and (3) a variety of lithologies available for investigation. An abandoned gas exploration well (GrSk 3/90) at Gross Schönebeck completely meets these requirements and gives access to hot, water-bearing Lower Permian successions. It was therefore selected from a suite of existing wells, reopened in December 2000, and deepened from 4264 $\mathrm{m}$ to $4309 \mathrm{~m}$ to serve as a geothermal in situ laboratory.

\section{Hydraulic Stimulation}

Nine months after the well was reopened, a re-equilibrated temperature of $149^{\circ} \mathrm{C}$ was measured at $4285 \mathrm{~m}$ depth. The formation pressure was determined from long-term pressure

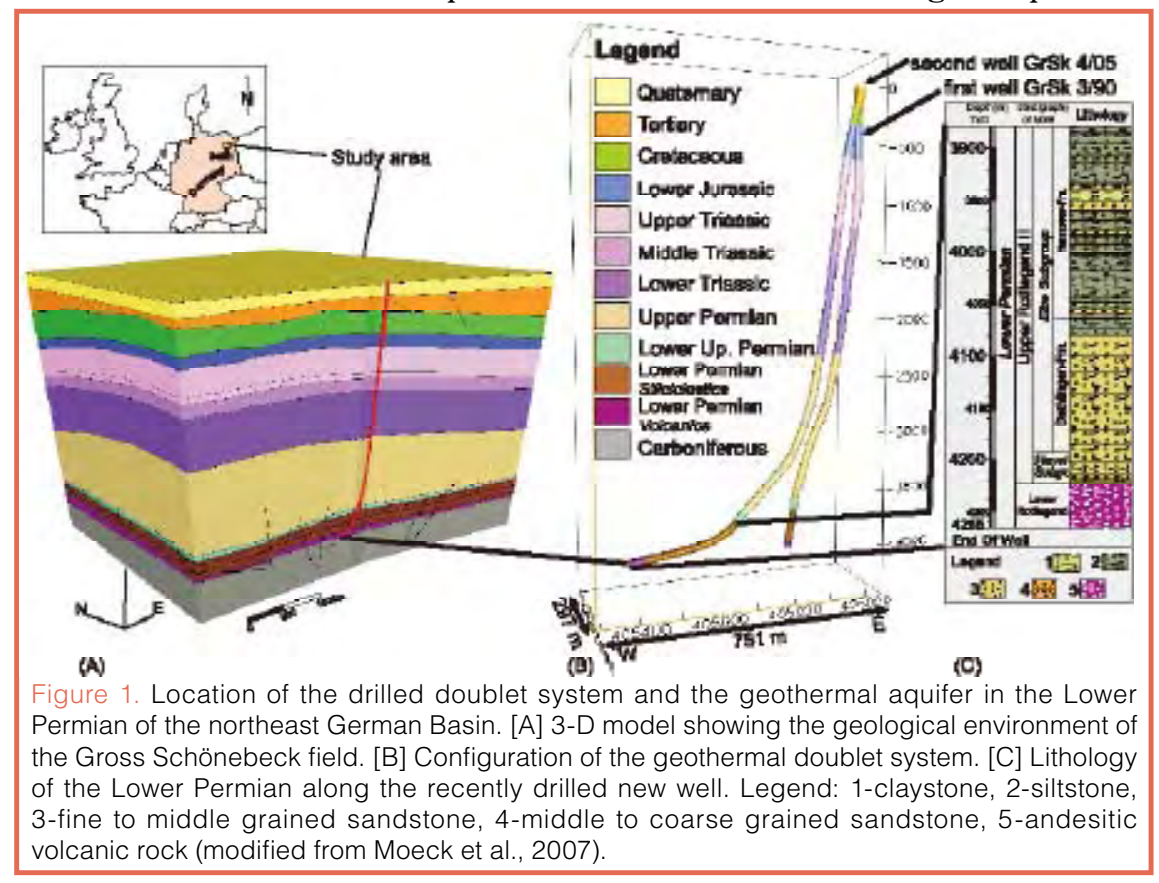


logs showing equilibrium conditions close to $44.9 \pm 0.3 \mathrm{MPa}$ at $4220 \mathrm{~m}$ depth. A series of stimulation experiments was performed. First, open hole hydraulic gel-proppant fracturing treatments were conducted in two pre-selected sedimentary reservoir zones in the Lower Permian sandstones at a depth of $\sim 4 \mathrm{~km}$. The main inflow zones could clearly be identified. In a second step, massive water fracturing treatments were applied over the entire open hole interval from $3874 \mathrm{~m}$ to $4309 \mathrm{~m}$ depth. Pressure response analyses and well logs indicated the creation of vertical fractures and a bilinear flow regime in the reservoir, implying that an enhanced geothermal system suitable for geothermal power production had formed (Zimmermann et al., 2005; Huenges et al., 2006).

\section{Directional Drilling of a Second Well}

Hydraulic-thermal modeling based on data from the first well, along with regional structural analyses, identified the best possible well path geometry for the second well (Zimmermann et al., 2007). The borehole was designed parallel to the minimum horizontal stress direction and perpendicular to potentially hydraulic fractures to decrease auxiliary energy requirements for the thermal water loop in the planned doublet. Furthermore, this setup provides a low risk of a temperature short circuit of the system within the projected thirty years of utilization. Due to infrastructural requirements, the new well (GrSk 4/05) was located at the same drill site as GrSk 3/90 (27 m distance) but with a bottom hole some $500 \mathrm{~m}$ apart due to the reservoir requirements. Therefore, the new drilling operations required (1) a large hole diameter due to the deep static water table of the reservoir and the respective withdrawal during production (housing for the submersible pump), (2) directional drilling to intersect the target horizon at the derived offset from the existing hole and to increase the inflow conditions through well inclination in addition to later multiple fracturing, and (3) a special drilling mud concept to avoid formation damage of the reservoir as much as possible.

Initially, the large hole diameter (23") drilling experienced difficulties in clay-dominated sections requiring pumping capabilities beyond $4000 \mathrm{~L} \mathrm{~min}^{-1}$. Complete casing cementation was necessary, because thermally induced stress from hot water might have caused casing damage on the noncemented pipes. Total fluid loss and uncontrolled hydrofracturing occurred during the bottom up cementation of the $16^{\prime \prime}$ crossover $13-3 / 8^{\text {" }}$ casing, conducted with a mean slurry density of $1450 \mathrm{~kg} \mathrm{~m}^{-3}$. Therefore, squeeze cementation was performed from top of the well to the former cement infiltration zone. The successful placement of the cement was controlled by thermal logging.

Following drilling of a 1600-m-thick Upper Permian evaporate section counterbalanced with a mud density of 2000 $\mathrm{kg} \mathrm{m}^{-3}$, a 9-5/8" liner was installed, which (despite a strength with a safety factor of 1.8 ) collapsed in the bottom region after reduction of the mud density was reduced to $1060 \mathrm{~kg}$ $\mathrm{m}^{-}{ }^{3}$. Presumably, this failure was caused by additional stress components from anisotropic stress from the well inclination of $\sim 20^{\circ}$ in connection with the presence of highly ductile rocksalt (temperatures of $110^{\circ} \mathrm{C}$ in $3800 \mathrm{~m}$ depth). Stress concentration in interbedded anhydritic layers might have increased anisotropic stresses. The collapsed 9-5/8" liner was replaced with a combined $7 "$ " $7-5 / 8$ " liner after sidetrakking. The latter caused further challenges, as the setting of the mechanical anchor of the whipstock required its modification for reliable operation in mud with $40 \%$ barite content. Furthermore, the borehole design needed to be adjusted due to the loss of one casing dimension. Therefore, the borehole was deepened with 5-7/8" diameter drilling into the geothermal reservoir of the Lower Permian section.

In order to avoid drilling mud which would invade the formation and reduce its permeability, the reservoir below $3900 \mathrm{~m}$ was drilled with a near-balanced mud density of $1030 \mathrm{~kg} \mathrm{~m}^{-3}$. Borehole wall breakouts at $3940 \mathrm{~m}$ forced a cleaning run and an elevation of mud pressure to $1100 \mathrm{~kg} \mathrm{~m}^{-3}$. This specific mud pressure was the result of a geomechanical study investigating the initiation of borehole breakouts in reservoir successions under low mud pressures (Moeck et al., 2007). Another reason for increasing the mud weight was the occurrence of $\mathrm{H}_{2} \mathrm{~S}$ below the $7-5 / 8^{\prime \prime}$ casing shoe and within the fissured lowermost Upper Permian formation. To prevent gas inflow, the mud density was partly increased up to $1200 \mathrm{~kg} \mathrm{~m}^{-3}$, and a specially designed marble flour-based mud was used to minimize fluid losses into the coarse sandstone formation. Due to the danger of differential sticking and formation damage, the mud weight was lowered in subsequent drilling operations. No significant fluid losses were observed during the final drilling and casing operations.

\section{Accessing the Geothermal Reservoir}

The well reached the target along the planned borehole track (Fig. 2). A 5 " liner combined with a non-cemented section of pre-perforated pipes at the bottom was installed in the lowermost section at $4400 \mathrm{~m}$ depth. The presence of Lower Permian middle to fine grained sandstones of the Dethlingen Formation at this depth was confirmed by cutting and well $\log$ analyses. In the well, the Lower Permian sediments reached a thickness of $340 \mathrm{~m}$ at the flank of structural high of the sandstones (Fig. 3). Reservoir sandstone layers with permeabilities up to $160 \mathrm{mD}$ lay within the succession and have

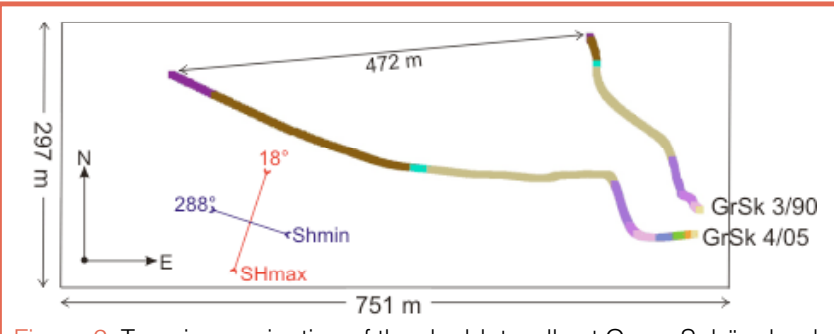

Figure 2. Top view projection of the doublet wells at Gross Schönebeck The deviation of GrSk 4/05 is parallel to the minimum horizontal stress direction to facilitate a set of parallel hydraulic fractures. 


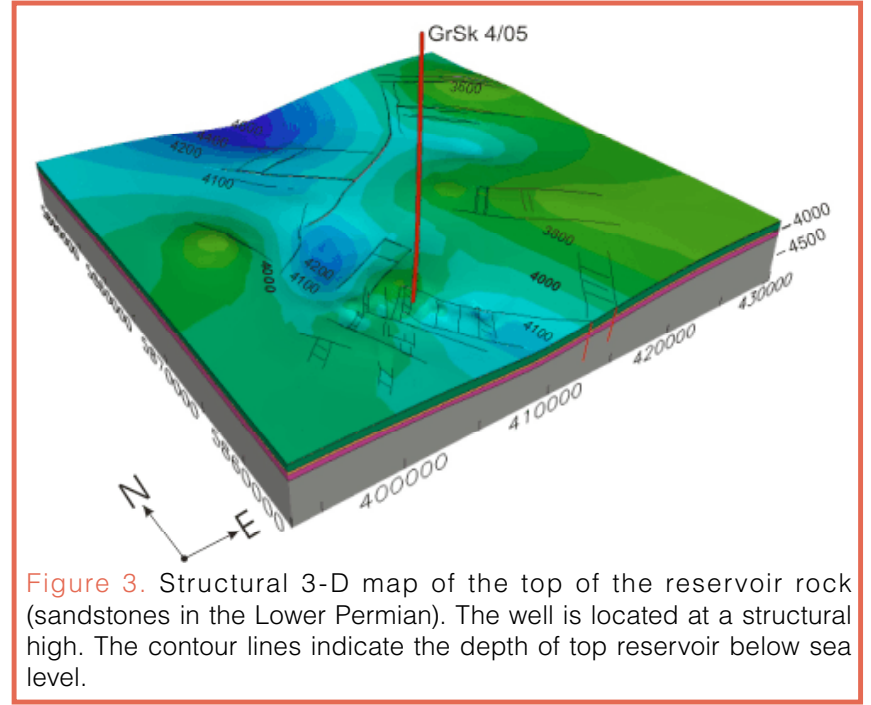

a vertical thickness of $>80 \mathrm{~m}$. The well inclination of $45^{\circ}$ implies that up to $150 \mathrm{~m}$ of the well is within this permeable sandstone. The well deviation is oriented at $288^{\circ}$ to optimize the hydraulic fracturing design (Fig. 2 and Holl et al., 2005). Hydrofracs are planned in the volcanic rock and some in the sandstones. Based on the previously mentioned hydraulicthermal modeling, a distance of no less than $450 \mathrm{~m}$ between the bottoms of the two wells was realized to avoid a thermal breakthrough of the injected cold water directly into the production well.

\section{Conclusions}

In the Northeast German Basin, 4000-m-deep Lower Permian sandstones and volcanic rocks have been explored for geothermal energy production near Gross Schönebeck. The research strategy we applied consists of (i) re-using a former gas exploration well for logging and hydraulic stimulation campaigns, (ii) understanding the reservoir behavior based on data recovery from hydraulic treatments, (iii) optimizing the planned reservoir exploitation by analyzing the performance variances of well paths, (iv) completing the geothermal doublet system by drilling a second well, (v) future stimulating and testing the new well and installing a thermal water loop using a doublet system, and (vi) installing a binary geothermal power plant if sufficient reservoir conditions are continued. The experiences gained, especially in (iv), show that drilling a large hole diameter (23") is feasible but challenging especially in clay dominated layers; that directional drilling can be applied as a standard operation; and that a variable mud concept needs to be applied in order to react to unforeseen operational requirements such as formation damage, breakouts, or inflows. In this project, technical and scientific challenges were successfully met, and the lessons that were learned provided essential knowledge for developing future drilling strategies in deep sedimentary geothermal systems, especially in the Central European Basin System.

\section{Acknowledgement}

The authors want to thank the German Federal Ministry for the Environment for funding (BMU ZIP 0327508, BMU 0329951B, BMU 0329991).

\section{Geothermal Project Group:}

Ernst Huenges, Inga Moeck, Ali Saadat, Wulf Brandt, Axel Schulz, Heinz-Gerd Holl, David Bruhn, Günter Zimmermann, Guido Blöcher, and Lothar Wohlgemuth.

\section{References}

Baumgärtner, J., Jung, R., Hettkamp, T., and Teza, D., 2004. The status of the Hot Dry Rock Scientific Power Plant at Soultzsous-Forêts. Z. Angew. Geol., 2:12-17.

Economides, M.J., and Nolte, K.G., 1989. Reservoir Stimulation. Houston, Texas (Schlumberger Educational Services).

Holl, H.-G., Moeck, I., and Schandelmeier, H., 2005. Characterisation of the tectono-sedimentary evolution of a geothermal reservoir - implications for exploitation (Southern Permian Basin, NE Germany). Proceedings World Geothermal Congress 2005, Antalya, Turkey, 24-29 April 2005, 1-5.

Huenges, E., and Kohl, T., 2007. Stimulation of reservoir and microseismicity - summary of the Ittingen workshop June 2006, ENGINE - Enhanced Geothermal Innovative Network for Europe, Mid-Term Conference Potsdam, Germany, 9-12 January 2007.

Huenges, E., Holl, H.-G., Legarth, B., Zimmermann, G., Saadat, A., and Tischner, T., 2004. The stimulation of a sedimentary geothermal reservoir in the North German Basin: case study Groß Schönebeck. Z. Angew. Geol., 2:24-27.

Huenges, E., Trautwein, U., Legarth, B., and Zimmermann, G., 2006. Fluid pressure variation in a sedimentary geothermal reservoir in the North German Basin: case study Groß Schönebeck. Pure Appl. Geophys., 163(10):1-12.

Moeck, I., Backers, T., and Schandelmeier, H., 2007. Assessment of mechanical wellbore stability by numerical analysis of fracture growth. Proc. EAGE 69th Conference \& Exhibition, London, 11-14 June 2007, D047: 1-5.

Zimmermann, G., Reinike, A., Blöcher, G., Milsch, H., Gehrke, D., Holl, H.-G., Moeck, I., Brandt, W., Saadat, A., and Huenges, E., 2007. Well path design and stimulation treatments at the geothermal research well GT GRSK 4/05 in Groß Schönebeck. Proc. 32nd Workshop on Geothermal Reservoir Engineering, Stanford University, Stanford, Calif., 22-24 January 2007, SGP-TR-183.

Zimmermann, G., Reinicke, A., Holl, H.-G., Legarth, B., Saadat, A., and Huenges, E., 2005. Well test analysis after massive Waterfrac treatments in a sedimentary geothermal reservoir, Proc. World Geothermal Congress 2005, Antalya, Turkey, 24-29 April 2005, 1-5.

\section{Authors}

Ernst Huenges, Inga Moeck, GFZ Potsdam, Telegrafenberg, D14473, Potsdam, Germany, e-mail: huenges@gfz-potsdam.de.

\section{Related Web Link}

http://www.gfz-potsdam.de/pb5/pb52/projects/Machbarkeit/ ewelcome.html 